\title{
REVIEW ARTICLE Overview of therapeutic drug research for COVID-19 in China
}

\author{
Heng $\mathrm{Li}^{1,2}$, Li Yang ${ }^{1}$, Fei-fei Liu ${ }^{1,2}$, Xin-na Ma ${ }^{3}$, Pei-lan $\mathrm{He}^{1}$, Wei Tang ${ }^{1}$, Xian-kun Tong ${ }^{1}$ and Jian-ping Zuo ${ }^{1,2,3}$ \\ Since the outbreak of novel coronavirus pneumonia (COVID-19) in December 2019, more than 2,500,000 people worldwide have \\ been diagnosed with SARS-CoV-2 as of April 22. In response to this epidemic, China has issued seven trial versions of diagnosis and \\ treatment protocol for COVID-19. According to the information that we have collected so far, this article provides an overview of \\ potential therapeutic drugs and compounds with much attention, including favipiravir and hydroxychloroquine, as well as \\ traditional Chinese medicine, which have been reported with good clinical treatment effects. Moreover, with further understanding \\ of SARS-CoV-2 virus, new drugs targeting specific SARS-CoV-2 viral components arise and investigations on these novel anti-SARS- \\ CoV-2 agents are also reviewed.
}

Keywords: SARS-CoV-2; COVID-19; novel coronavirus pneumonia; therapeutic drugs; anti-SARS-CoV-2 agents; favipiravir; hydroxychloroquine; traditional Chinese medicine

Acta Pharmacologica Sinica (2020) 41:1133-1140; https://doi.org/10.1038/s41401-020-0438-y

\section{INTRODUCTION}

In December 2019, a new type of unexplained pneumonia appeared in the South China Seafood Wholesale Market in Wuhan, Hubei Province, but its source has not yet been found. To confirm the cause, whole-genome sequencing of samples from patients with this unexplained pneumonia revealed a betacoronavirus that had never been seen before, which was different from SARS-CoV and MERS-CoV [1]. After the alert of this new pathogen, China quickly took measures to completely block off Hubei Province and implemented a quarantine policy nationwide to keep the outbreak under control. This efficient process was also recognized by the international WHO. This highly contagious new coronavirus was initially named 2019-nCoV. On Feb 11, 2020, the International Committee on Taxonomy of Viruses introduced the name "severe acute respiratory syndrome coronavirus 2" (SARSCoV-2) to refer to the virus, and the WHO named the related pneumonia coronavirus pneumonia (COVID-19).

This article will go through basic virology of SARS-CoV-2 and review mainly the drugs used in the battle against COVID-19 in China.

\section{VIROLOGY}

By genome sequencing, it was found that SARS-CoV-2 has $82 \%$ sequence similarity with SARS-CoV $[2,3]$, and through phylogenetic tree analysis, it has $96 \%$ homology with bat coronaviruses at the genome level, for which reason bats were inferred to be the host for SARS-CoV-2 [4]. The genome structure of SARS-CoV-2 is shown in Fig. 1.

SARS-CoV-2 is a single-stranded positive-sense RNA virus and is classified in the order Nidovirales, Coronaviridae, and Coronavirus [5]. Coronaviruses are a large class of viruses that can infect mammals and birds and can cause many diseases, such as respiratory, intestinal, liver, and nervous system diseases [6]. Coronaviruses are divided into four groups: alpha-, beta-, gamma- and delta-coronaviruses [7], and all known human pathogenic coronaviruses are beta-coronaviruses.

The single-stranded RNA genome of SARS-CoV-2 is 29891 nucleotides in size. The genes of SARS-CoV-2 from $5^{\prime}$ to $3^{\prime}$ are a $5^{\prime}$ untranslated region, including $5^{\prime}$ leader sequences; and open reading frame (ORF) $1 \mathrm{a} / \mathrm{b}$; structural proteins, including the envelope glycoprotein spike (S), envelope (E), membrane (M) and nucleoprotein (N); accessory proteins, such as ORF3, 6, 7a, 7b, 8 , and $9 \mathrm{~b}$; and a $3^{\prime}$ untranslated region [3].

ORF1a/b occupy two-thirds of the viral genome, and they encode two polyproteins, pp1a and pp1ab [8]. These two polyproteins can be hydrolyzed into 16 nonstructural proteins (nsps), including papain-like protease (PLpro), 3C-like protease (3CLpro), RNA-dependent RNA polymerase (RdRp), helicase, and exonuclease [6]. The enveloped glycoprotein spike (S) forms a layer of glycoproteins protruding from the envelope and is closely related to virus infection of cells [9]. There are multiple sequence segments in the receptor-binding domain of the $S$ protein, which have high homology with SARS-CoV sequences, and some studies have confirmed that SARS-CoV-2 can bind to the ACE2 receptor on the cell surface, similar to SARS-CoV $[1,3,10]$. Two additional transmembrane glycoproteins, envelope $(E)$ and membrane $(M)$, are incorporated into the virion. Nucleoprotein encapsulates the viral $(+)$ RNA genome in the form of a spiral in the envelope to prevent degradation. Accessory proteins do not participate in viral replication, but they interfere with the host innate immune response or have other unknown functions [10].

The SARS-CoV-2 possible life cycle begins when the spike glycoprotein on the envelope binds to the ACE2 receptor, and membrane fusion occurs either directly with the host cell

\footnotetext{
'Laboratory of Immunopharmacology, Shanghai Institute of MateriaMedica, Chinese Academy of Sciences, Shanghai 201203 , China; ${ }^{2}$ University of Chinese Academy of Sciences, Beijing 100049, China and ${ }^{3}$ Laboratory of Immunology and Virology, Shanghai University of Traditional Chinese Medicine, Shanghai 201203, China Correspondence: Xian-kun Tong (xktong@simm.ac.cn) or Jian-ping Zuo (jpzuo@simm.ac.cn)
}

Received: 17 March 2020 Accepted: 10 May 2020

Published online: 17 June 2020 
membrane or with the endosome membrane. After membrane fusion, the viral RNA genome is released into the cytoplasm, and the uncoated RNA is translated into two polyproteins. The polyproteins are cleaved by the protease encoded by ORF1a into the 16 nsps, which can form an RNA replicase-transcriptase complex $[6,10]$. This complex drives the production of negative-sense RNA, which is used as a template for the full-length (+) RNA genome. During transcription, subgenomic RNAs are produced by discontinuous transcription and then transcribed into subgenomic (+) mRNA, which is translated into different structural proteins. The newly formed structural protein and viral genomic RNA combine to form a nucleocapsid. The viral particles bud into the ER-Golgi intermediate compartment (ERGIC), and then the primary virion is released from the infected cells [10]. A diagram of SARS-CoV-2 life cycle is shown in Fig. 2.

\section{OVERVIEW OF COVID-19 DRUG-RELATED CLINICAL TRIALS IN CHINA}

Due to the sudden emergence of SARS-CoV-2, no specific antiviral agents are available. However, many drugs under development are believed to have potential anti-SARS-CoV-2 activity due to common biological processes in the virus life cycle. Currently, there are 200 domestic clinical trials of COVID-19 drugs from the Chinese Clinical Trial Registry (ChiCTR) as of 10 March, and most are for chemical drugs, Chinese patent medicines, and combinations. All of these clinical trials were registered in 2020, after the outbreak of COVID-19 [11].

Among those COVID-19 treatment-related clinical trials, a total of 155 registered COVID-19 treatment drug-related interventional studies were obtained from the ChiCTR database (www.chictr.org. cn) with ethics committee approval and informed consent signed by 10 March. Statistic information of these registered trials are shown in Fig. 3. The study phase of each trial was extracted, and nearly $25 \%$ of these clinical trials were registered as phase 4 studies, which were stated as "postmarketing drugs" or "phase IV clinical trials" by the ChiCTR definition. In phase four studies, many domestically approved Chinese patent drugs and chemical agents are being used to treat COVID-19 patients.

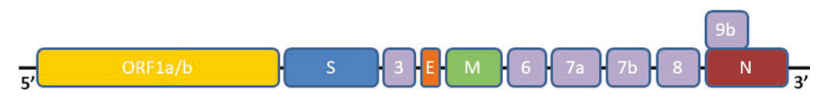

Fig. 1 The genome of SARS-CoV-2 [3].
With so many clinical trials registered in such a short period of time, we can see that China has responded to the epidemic in a timely manner and hopes to find SARS-CoV-2-specific medicines to end the epidemic as soon as possible. This urgent need propelled China's drug research ability to its full power, and this motivation involved many academic institutions, hospitals, and companies. This approach has also led to concerns about this phenomenon. Excessive research and drug trials can create the problem of squeezing each other for limited medical resources or even wasting them. This phenomenon and its impact on our medical system, as well as possible improvement in our medical administration, need thorough review and discussion at an appropriate time in the future.

In these 155 pooled clinical trials, a number of approved chemical and biomacromolecule drugs have been used in COVID19 treatment clinical trials for drug repurposing, most of which are nucleotide analogs and protease inhibitors against other viral pathogens, including influenza virus, HIV and HCV. Comprehensive information about the chemical agents used in COVID-19 drug clinical trials is shown in the table below (Table 1).

\section{ANTIVIRAL AGENTS SUGGESTED IN THE NATIONAL PROTOCOL FOR COVID-19 TREATMENT}

Although the mortality rate of SARS-CoV-2 is not as high as that of SARS-CoV and MERS-CoV, SARS-CoV-2 is more contagious, and studies have shown that it can be transmitted during the incubation period [12].

To date, there are no specific vaccines or antiviral drugs against COVID-19. For the treatment of patients, isolation and symptomatic supportive care are currently recommended, including oxygen therapy, water, and dielectric balance, nutritional interventions and fluid management to reduce symptoms and prevent end-organ dysfunction [13, 14]. For the treatment of severe pneumonia, extracorporeal membrane oxygenation therapy is a new type of adjuvant treatment technology [15], and gas exchange through cardiopulmonary bypass technology can reduce ventilator-related damage and oxygen toxicity damage to promote early patient recovery. However, the needs for specific technical skill and high expense limit its usage.

A number of nonspecific antiviral agents have been recommended in the latest 7th trial version of the "Diagnosis and Treatment Protocol for Novel Coronavirus Pneumonia". Table 2 shown below lists important information about currently available anti-SARS-CoV-2 drugs (Table 2).

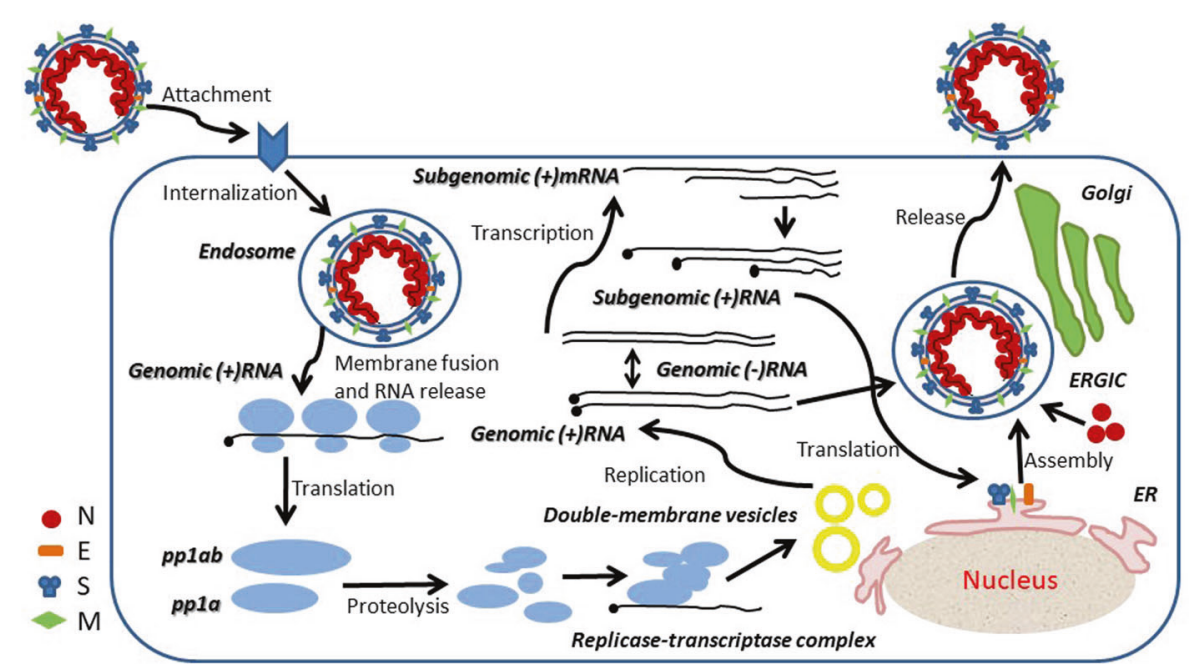

Fig. 2 The possible life cycle of SARS-CoV-2 [10]. 


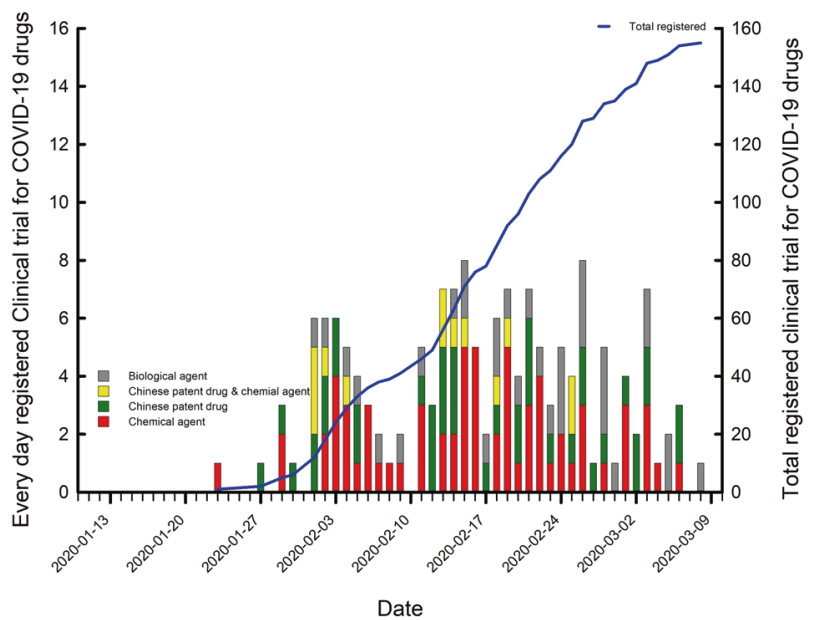

Fig. 3 Registered clinical trials for COVID-19 drugs [11]. Clinical trials with ethics committee approval and signed informed consent were pooled from the ChiCTR database (www.chictr.org.cn) (as of $10 \mathrm{Mar}$ ), and drugs involved in these trials were identified and categorized manually.

\section{IFN-a}

Type I interferons, including IFN- $\alpha$ and IFN- $\beta$, have broad-spectrum antiviral effects [16]. IFN- $a$ can directly inhibit virus replication or can achieve antiviral effects by activating innate or adaptive immunity [17]. Many studies have proven that IFN-a has an antiviral effect on SARS-CoV [18], and other experts discovered that IFN-a can prevent MERS-CoV infection and effectively inhibit the virus in the early stages of infection [19]. Because it is also a coronavirus and highly homologous to SARS-CoV, IFN- $a$ is recommended for the treatment of SARS-CoV-2 infection. According to the latest new "Diagnosis and Treatment Protocol for Novel Coronavirus Pneumonia", IFN- $a$ at a dose of $\sim 5$ million U or equivalent dose each time for adults is added to $2 \mathrm{~mL}$ of sterile water, and it is aerosolized and inhaled twice a day [13].

\section{Lopinavir/ritonavir}

Lopinavir was first approved in the United States in 2000 for the treatment of HIV infection [20]. It is a protease inhibitor and is usually used in combination with ritonavir to increase its half-life through the inhibition of cytochrome P450 [21]. In vitro studies have shown that lopinavir/ritonavir can inhibit the replication of MERS-CoV and SARS-CoV and exert antiviral effects [22-25]. At present, the drug has been used in the clinical treatment of COVID-19 at a dose of $400 \mathrm{mg} / 100 \mathrm{mg}$ for adults twice daily, and the course of treatment does not exceed 10 days [13]. However, this treatment has certain toxic and side effects on the treatment of COVID-19. Therefore, its safety and effectiveness require further research. Recently, some clinical studies have shown that lopinavir/ritonavir treatment has no significant effect $[26,27]$.

\section{Ribavirin}

Ribavirin is a purine nucleoside analog with a broad-spectrum antiviral effect [28]. It is used mainly to treat respiratory syncytial virus infection [29] and in combination with interferon for hepatitis C [30]. Ribavirin was widely used in 2003 to treat SARSCoV infection, but when used alone, it seemed to have no effect and caused significant hemolysis in many patients [31-34]. When ribavirin was combined with IFN- $\beta$, it had good antiviral activity in in vitro studies [35]. Some studies have shown that in patients with severe MERS-CoV infection, ribavirin combined with IFN-a-2a treatment can significantly improve patient 14-day survival [36]. Preliminary in vitro test results demonstrate that ribavirin can inhibit SARS-CoV-2 in a human cell line. In the latest "Diagnosis and Treatment Protocol for Novel Coronavirus Pneumonia", it is recommended to use ribavirin at a dose of $500 \mathrm{mg}$ each time for adults and in combination with interferon or lopinavir/ritonavir, with 2-3 intravenous infusions daily. The course of treatment does not exceed 10 days [13].

\section{Chloroquine phosphate}

Chloroquine phosphate is an antimalarial drug that has been on the market for many years, and it also has a potential broadspectrum antiviral effect $[37,38]$. It can increase the $\mathrm{pH}$ of lysosomes to prevent virus fusion with the cell membrane and then block virus entry and infection [39].

Some studies have found that the spike glycoprotein on the virus envelope binds to the ACE2 receptor to mediate SARS-CoV-2 infection $[9,40]$. Chloroquine phosphate has been reported to interfere with the glycosylation of the ACE2 receptor, thereby inhibiting the binding of SARS-CoV to cells and achieving therapeutic goals [41]. Therefore, chloroquine phosphate is used to treat COVID-19, and in vitro experiments show that chloroquine phosphate does inhibit SARS-CoV-2 and that its $\mathrm{EC}_{50}$ is $1.13 \mu \mathrm{M}$ [39]. Apart from the above antiviral mechanism, chloroquine phosphate can continue to exert antiviral effects after SARS-CoV-2 invades cells, and it also has immunomodulatory activity to strengthen the antiviral effect [42]. Therefore, chloroquine phosphate has been included in the "Diagnosis and Treatment Protocol for Novel Coronavirus Pneumonia" and is undergoing clinical trials. Chloroquine phosphate is used for the treatment of COVID-19 in adults aged 18-65 years. Those who weigh more than $50 \mathrm{~kg}$ will receive $500 \mathrm{mg}$ twice daily for 7 days, while those who weigh less than $50 \mathrm{~kg}$ will receive $500 \mathrm{mg}$ twice daily on days 1 and 2 and $500 \mathrm{mg}$ once daily on days 3-7 [13].

\section{Arbidol}

Arbidol is a non-nucleoside broad-spectrum antiviral drug for upper respiratory tract infections caused by influenza $A$ and $B$ viruses, and it was first approved in Russia [43]. It can inhibit the adhesion of viruses to host cells and prevent them from invading human cells [44]. At the same time, it can promote the synthesis of interferon, which can prevent influenza virus invasion and treat influenza virus infection [45]. Some studies have confirmed that arbidol has a good effect against SARS-CoV and MERS-CoV infections [46, 47]. Chinese scientists found in in vitro cell experiments that compared with a drug-untreated control group, $10-30 \mu \mathrm{M}$ arbidol can effectively inhibit SARS-CoV-2 up to 60 times and significantly inhibit the pathological effects of the virus on cells [48]. As described in the latest "Diagnosis and Treatment Protocol for Novel Coronavirus Pneumonia", arbidol is used at a dose of $200 \mathrm{mg}$ for adults three times daily, and the course of treatment does not exceed 10 days [13]. It has been reported that some patients have improved symptoms after receiving arbidol [49].

\section{ANTICIPATED ANTIVIRAL AGENTS}

Favipiravir

Favipiravir is a nucleoside analog $[50,51]$ with an ability to inhibit RNA-dependent polymerase [52] and was approved for marketing in Japan in 2014. It is used for antiviral treatment of influenza A and $B$ [52] and can effectively inhibit Ebola virus, yellow fever virus [53], etc. In vitro experiments have shown that favipiravir is effective for COVID-19 and that its $\mathrm{EC}_{50}$ is $61.88 \mu \mathrm{M}$ [39]. To date, some clinical trials of favipiravir in the treatment of COVID-19 have been carried out in China. Recent clinical studies have found that compared with the antiviral drug arbidol, the clinical effect of favipiravir is more significant. Nucleic acid positive-to-negative time, mean antipyretic time and cough remission time were all better than those of the arbidol group [27]. 
Table 1. Approved drugs used in COVID-19 repurpose clinical trials.

\begin{tabular}{|c|c|c|c|}
\hline Category & Drug name & Approved indication & Mechanism \\
\hline \multirow[t]{4}{*}{ Biomacro-molecule } & Tocilizumab & Rheumatoid arthritis & IL-6R antibody \\
\hline & $\begin{array}{l}\text { Type I interferon (include IFN- } \alpha \\
\& \text { IFN- } \beta \text { ) }\end{array}$ & $\begin{array}{l}\text { Hairy cell leukemia, melanoma, AIDS-related } \\
\text { Kaposi's sarcoma }\end{array}$ & Immune modulation \\
\hline & Thymosin a1 & $\mathrm{T}$ cell defect, autoimmunity disease & $\mathrm{T}$ cell stimulation \\
\hline & rhG-CSF & Leukopenia & CSF receptor \\
\hline \multirow[t]{26}{*}{ Chemical Agent } & Lopinavir/ritonavir & HIV & HIV-1 protease inhibitor \\
\hline & Emtritabine & HIV & Reverse transcriptase inhibitor \\
\hline & Azvudine & HIV & Reverse transcriptase inhibitor \\
\hline & Ribavirin & $\mathrm{HCV}$ & $\mathrm{RdRp}^{\mathrm{a}}$ inhibitor \\
\hline & Danorevir & $\mathrm{HCV}$ & HCV protease inhibitor \\
\hline & Ganovo & $\mathrm{HCV}$ & HCV protease inhibitor \\
\hline & Tenofovir & HBV & Reverse transcriptase inhibitor \\
\hline & Triazavirin & Flu & RdRp inhibitor \\
\hline & Favipiravir & Flu & RdRp inhibitor \\
\hline & Baloxavir Marboxil & Flu & $\begin{array}{l}\text { Influenza virus cap-dependent } \\
\text { endonuclease inhibitor }\end{array}$ \\
\hline & Arbidol & Flu & Virion entry inhibitor \\
\hline & Poly (I:C) Injection & Viral infection & Immune modulation \\
\hline & Carrimycin & Bacteria infection & Peptide acyltransferase inhibitor \\
\hline & Dihydroartemisinine/Piperaquine & Malaria & Multiple targets \\
\hline & Chloroquine $^{\mathrm{b}}$ & Malaria & Heme biocrystallization inhibitor \\
\hline & Suramin & Trypanosomes infection & Multiple targets \\
\hline & Ruxolitinib & Myelofibrosis & JAK1/JAK2 signaling inhibition \\
\hline & Leflunomide & Rheumatoid arthritis & Pyrimidine synthesis inhibitor \\
\hline & Tranilast & Bronchial asthma, Allergic disorders & $\begin{array}{l}\text { Hematopoietic prostaglandin D synthase } \\
\text { inhibitor }\end{array}$ \\
\hline & Ebastine & Allergic rhinitis, Chronic idiopathic urticaria & Histamine $\mathrm{H}_{1}$-receptor antagonist \\
\hline & Alpha lipoic acid & Diabetic multiple peripheral neuropathy & Antioxidant \\
\hline & Pirfenidone & Idiopathic pulmonary fibrosis & $\begin{array}{l}\text { Collagen synthesis inhibition, Cytokine } \\
\text { down-regulation }\end{array}$ \\
\hline & Bismuth potassium citrate & Gastric ulcer & Gastric mucosa protectant \\
\hline & Enoxaparin Sodium Injection & Venous thromboembolic disease & Xa factor inbihitor \\
\hline & Glycyrrhizinate & Premenstrual syndrome, Viral infections & Multiple targets \\
\hline & Glucocorticoid & Inflammatory conditions & Glucocorticoid receptor \\
\hline
\end{tabular}

Table 2. Current suggested drugs in COVID-19 treatment ${ }^{\mathrm{a}}$.

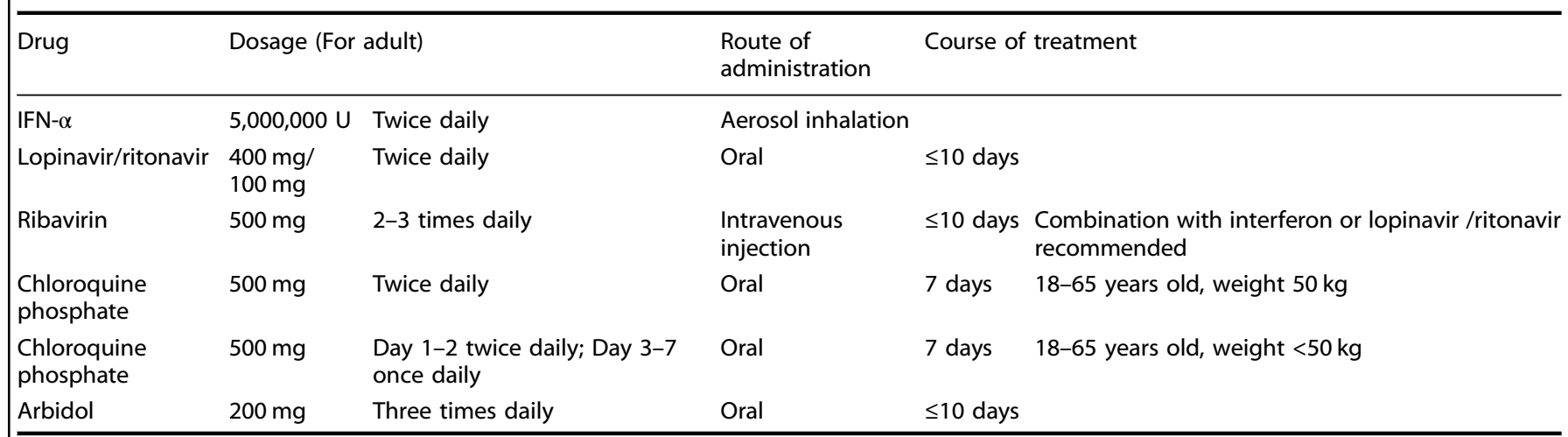

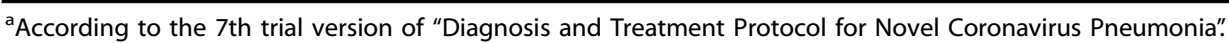


Remdesivir(GS-5734)

Remdesivir was first used to treat Ebola virus, and it has completed phase 2 clinical trials [54]. As a nucleoside analog, it can interact with $\operatorname{RdRp}[55,56]$, and the triphosphate form of remdesivir will compete with adenosine triphosphate, leading to delayed chain termination and inhibiting viral replication and transcription [57]. A number of in vitro studies have shown that remdesivir has inhibitory effects on a variety of human and animal coronaviruses $[58,59]$. An in vivo study of remdesivir against SARS-CoV showed that remdesivir can reduce virus levels in the lungs of mice infected with SARS-CoV and reduce lung function damage caused by the virus [60]. Moreover, some studies have found that the antiviral effect of remdesivir against MERS-CoV is better than that of lopinavir/ritonavir combined with IFN- $\beta$ [21].

According to the above evidence, remdesivir has been used to treat SARS-CoV-2, and in vitro experiments showed that remdesivir has a good inhibitory effect on SARS-CoV-2, with an $\mathrm{EC}_{50}$ of $0.77 \mu \mathrm{M}$ [39]. Recently, the first COVID-19 patient in the United States was treated with remdesivir on the 7th day of hospitalization, and their clinical symptoms were improved significantly [61]. At present, a phase three clinical trial of remdesivir for COVID-19 has been officially launched in China, and a total of 761 patients are planned to be enrolled in the study, which will be randomized, double-blind and placebo-controlled [62].

\section{Hydroxychloroquine}

As a derivative of chloroquine, hydroxychloroquine has similar efficacy and few adverse reactions. Based on its characteristics of immunomodulation, antithrombotic activity, and improved inflammation, hydroxychloroquine has been used in the clinical treatment of systemic lupus erythematosus [63]. Hydroxychloroquine has been shown to have anti-SARS-CoV activity in vitro [64], and it is clinically safer than chloroquine $[65,66]$. Some clinical studies have found that after treatment with hydroxychloroquine, the viral load significantly decreases or even disappears, and azithromycin can enhance the antiviral effect $[67,68]$.

\section{TRADITIONAL CHINESE MEDICINE (TCM)}

Traditional Chinese medicine has played an important role in the treatment of previous outbreaks of viral infectious diseases, so it has once again received attention during this epidemic of COVID$19[69,70]$. In response to the outbreak, Chinese medicine experts provided different Chinese medicine prescriptions and proprietary Chinese medicines for selection at different stages of the clinical treatment period of diagnosed patients according to the principle of TCM syndrome differentiation. For example, for patients with fatigue and fever during the medical observation period, Jinhua Qinggan granules, Lianhua Qingwen capsules (granules) and Shufeng Jiedu capsules (granules) can be used, while for patients with fatigue and gastrointestinal discomfort, the Chinese patent medicine Huoxiang Zhengqi capsules (pills, liquid, and oral solution) can be used [13].

Lianhua Qingwen capsules contain many Chinese herbal ingredients with antiviral effects, such as licorice. Glycyrrhizic acid, an extract of licorice, has been shown to inhibit virus replication and has been used clinically to treat HCV infection [71]. Glycyrrhizic acid has been reported to inhibit the replication of SARS-CoV in vitro [72]. For the reasons above, Lianhua Qingwen capsules have been used in the clinic and have a certain effect on improving clinical symptoms because they can obviously alleviate the symptoms of cough, fever, and fatigue in patients with COVID19 , reduce the proportion of severe cases, and shorten fever time [73-75].

In addition, lung cleansing and detoxifying decoction is also recommended for the treatment of confirmed cases in the latest "Diagnosis and Treatment Protocol for Novel Coronavirus Pneumonia" [13].

In addition to traditional Chinese medicine prescriptions, some traditional Chinese medicine ingredients also have certain potential for the treatment of SARS-CoV-2. Baicalin is a flavonoid compound isolated from the root of Scutellaria baicalensis and has been confirmed to inhibit SARS-CoV in vitro [76]. Ginsenoside improves human immunity and has a curative effect on viral infection [77].

Therefore, traditional Chinese medicine can also be used as an option to treat COVID-19. Many clinical trials have been launched to further analyze the safety and effectiveness of traditional Chinese medicine, and the traditional Chinese medicines mentioned above have been recommended in the latest "Diagnosis and Treatment Protocol for Novel Coronavirus Pneumonia" [13] (Table 3).

\section{Chinese patent medicine}

Chinese patent medicine is herbal medicines in traditional Chinese medicine modernized into a ready-to-use form, such as tablets, oral solutions, or dry suspensions. Chinese patent medicine has played very important roles in the domestic battle against COVID19 in China, and many clinical investigations have started to more precisely evaluate its effects on COVID-19 patient treatment. Chinese patent medicine, as well as many herbal medicines, has been very useful in improving symptoms such as coughing, weakness, and digestive system disorders, as well as alleviating anxiety. Reports announced that up to $90 \%$ of COVID-19 patients in China have been given Chinese patent medicine or TCM prescriptions. A list of Chinese patent medicine currently undergoing COVID-19 clinical trials is shown below (Table 4) to present an overall message about Chinese patent medicine in COVID-19 treatment research (Table 2 ).

\section{POTENTIAL ANTI-SARS-COV-2 TARGETS}

Spike protein

Some studies have confirmed that SARS-CoV-2 infects cells through endocytosis via the ACE2 receptor on AT2 alveolar epithelial cells in the lungs [78, 79]. At present, the protein structure of the S protein and ACE2 interaction has been solved, providing reliable guidance for vaccine and drug design [80]. Aiming at the mutual use of the $S$ protein and ACE2 protein necessary for SARS-CoV-2 to enter host cells, multiple domestic research teams have discovered a variety of potential ACE2-

Table 3. Currently suggested Chinese patent medicine in COVID-19 treatment ${ }^{\mathrm{a}}$.

\begin{tabular}{ll}
\hline Clinical symptom & Suggested Chinese patent medicine \\
\hline Medical observation period & $\begin{array}{l}\text { Huoxiang Zhengqi capsules (pills, liquid, oral solution); Jinhua Qinggan granules; Lianhua Qingwen } \\
\text { capsules (granules); Shufeng Jiedu capsules (granules) } \\
\text { Xiyanping injection; Xuebijing injection; Reduning injection; Tanreqing injection; Xingnaojing injection } \\
\text { Severe cases } \\
\text { Critical cases } \\
\text { Shengmaing injection; Reduning injection; Tanreqing injection; Xingnaojing injection; Shenfu injection; }\end{array}$ \\
\hline according to the 7th trial version of "Diagnosis and Treatment Protocol for Novel Coronavirus Pneumonia".
\end{tabular}


Table 4. Chinese patent medicine used in COVID-19 clinical trials ${ }^{\mathrm{a}}$.

\begin{tabular}{ll}
\hline Registration number & Chinese patent medicine \\
\hline ChiCTR2000029769 & Babaodan capsules \\
ChiCTR2000030704 & Bufonis Venenum injection \\
ChiCTR2000029822 & Honeysuckle decoction \\
ChiCTR2000030545 & Honeysuckle oral solution \\
ChiCTR2000029755 & Jingye Baidu granules \\
ChiCTR2000030255 & Jingyin granules \\
ChiCTR2000029781 & Kangbingdu granules \\
ChiCTR2000029991 & Keqing capsules \\
ChiCTR2000029991 & Kesuting syrup \\
ChiCTR2000030469 & Liushenwan \\
ChiCTR2000030022 & Pediatric Huatanzhike granules \\
ChiCTR2000029589 & Reduning injection \\
ChiCTR2000030043 & Shenfu injection \\
ChiCTR2000029780 & Shenqi Fuzheng injection \\
ChiCTR2000029605 & Shuanghuanglian oral solution \\
ChiCTR2000029742 & Sodium Aescinate injection \\
ChiCTR2000029813 & Tanreqing capsules \\
ChiCTR2000029432 & Tanreqing injection \\
ChiCTR2000030033 & Xiangxue antiviral oral solution \\
ChiCTR2000029756 & Xiyanping injection \\
ChiCTR2000029381 & Xuebijing injection \\
ChiCTR2000029434 & Lianhua Qingwen capsules (granules) \\
\hline Ch & S
\end{tabular}

${ }^{a}$ Chinese patent medicine used in 155 pooled COVID-19 clinical trials (either alone or in combination with other drugs) were listed.

binding agents through molecular docking virtual screening methods and artificial intelligence drug screening methods.

Papain-like protease (PLpro)

PLpro is a multifunctional protein with protease and phosphatase activity that is involved in viral replication and IFN antagonism [81]. PLpro of SARS-CoV-2 and SARS-CoV have only $83 \%$ sequence similarity [82]. However, the high-level structure of the protein that forms the active site is not altered in the two PLpro proteins [83]. There are already domestic teams working to find potential inhibitors of PLpro through virtual screening, which needs to be confirmed by experiments.

$3 C$-like protease (3CLpro)

The 3CLpro of SARS-CoV-2 and SARS-CoV have an amino acid sequence similarity of up to $96 \%$, and the structure of 3CLpro in SARS-CoV-2 has been solved [82]. 3CLpro is a key protein of the virus, and the virus needs to use it to replicate RNA. Therefore, finding SARS-CoV-2 3CLpro inhibitors can provide a more effective way to fight COVID-19.

RNA-dependent RNA polymerase (RdRp)

As an RNA virus, SARS-CoV-2-encoded RdRp plays a key role in the virus's RNA replication. RdRp inhibitors can be used as broadspectrum antiviral drugs against RNA viruses. The RdRp protein structure has a large and deep groove structural region as the active center of RNA synthesis. The sequence similarity of the RdRp proteins of SARS-CoV-2 and SARS-CoV is as high as $96 \%$, and structural differences exist outside the active center [82]. Therefore, high sequence conservation allows the development of RdRp inhibitors against SARS-CoV to be applied to the development of anti-SARS-CoV-2 drugs.
TMPRSS2 (serine protease)

A recent study showed that in addition to the use of the SARS-CoV receptor ACE2 to enter the cell, SARS-CoV-2 has two other proteins, cathepsin $B$ and $L(C a t B / L)$ and TMPRSS2, that activate the $\mathrm{S}$ protein, help SARS-CoV enter the cell, and play a key role in the process of invasion of normal cells by SARS-CoV-2 [84]. When a TMPRSS2 inhibitor is used in combination with a CatB/L inhibitor, they can completely inhibit the invasion of SARS-CoV-2. Therefore, TMPRSS2 may be a potential antiviral target.

\section{PERSPECTIVE}

This article provides an overview of published information on domestic research and the development of coronavirus-related therapeutic agents. The drug-repurposing effort summarized in this article focused primarily on agents currently known to be active against other RNA viruses, including SARS-CoV, MERS-CoV, influenza, HCV, and Ebola, as well as anti-inflammatory drugs. This information provides a strong intellectual groundwork for support of current and future research and development for the discovery and development of therapeutic agents for the treatment of COVID-19 and coronavirus-related diseases. However, there are still no officially approved specific antiviral drugs or vaccines for SARS-CoV-2, and supportive care remains a key to treatment. TCM has accumulated thousands of years of experience in the treatment of pandemic and endemic diseases. Complementary and alternative treatments are still urgently needed for the management of patients with SARS-CoV-2 infection, and experiences in TCM are certainly worth examining. Many antiviral Chinese patent medicines, such as Shuanghuanglian oral solution and others, have been declared to have the effect of heat clearing and detoxifying, which could help clear viral respiratory pathogens and relieve symptoms according to TCM theory. Chinese patent medicine has been used in many historic epidemics, such as the previous two coronavirus outbreaks (SARS-CoV in 2013 and MERS-CoV in 2012) and seasonal epidemics caused by influenza viruses and dengue virus. Fighting against current epidemics also provides an opportunity to test the true value of TCM in treating emerging contagious diseases. It is encouraging that controlled clinical studies to evaluate the efficacy of TCM in the treatment of SARS-CoV were conducted and reported. We believe that specific and efficient antiviral drugs and therapy will arise from these ongoing and developing drugs, especially from the rich tradition of herbal medicines in China.

\section{ADDITIONAL INFORMATION}

Competing interests: The authors declare no competing interests.

\section{REFERENCES}

1. Xu X, Chen P, Wang J, Feng J, Zhou H, Li X, et al. Evolution of the novel coronavirus from the ongoing Wuhan outbreak and modeling of its spike protein for risk of human transmission. Sci China Life Sci. 2020;63:457-60.

2. Zhang N, Wang L, Deng $X$, Liang $R$, Su M, He $C$, et al. Recent advances in the detection of respiratory virus infection in humans. J Med Virol. 2020;92:408-17.

3. Chan JFW, Kok KH, Zhu Z, Chu H, To KKW, Yuan S, et al. Genomic characterization of the 2019 novel human-pathogenic coronavirus isolated from a patient with atypical pneumonia after visiting Wuhan. Emerg Microbes Infect. 2020;9:221-36.

4. Zhou $P$, Yang XL, Wang XG, Hu B, Zhang L, Zhang W, et al. Discovery of a novel coronavirus associated with the recent pneumonia outbreak in humans and its potential bat origin. bioRxiv 2020: 2020.01.22.914952.

5. Weiss SRLJ. Coronavirus pathogenesis. Adv Virus Res. 2011;81:85-164.

6. Fehr AR, Perlman S. Coronaviruses: an overview of their replication and pathogenesis. Methods Mol Biol. 2015;1282:1-23.

7. Yin Y, Wunderink RG. MERS, SARS and other coronaviruses as causes of pneumonia. Respirology. 2018;23:130-7.

8. Perlman S, Netland J. Coronaviruses post-SARS: update on replication and pathogenesis. Nat Rev Microbiol. 2009;7:439-50. 
9. de Wilde $A H$, Snijder EJ, Kikkert M, van Hemert MJ. Host factors in coronavirus replication. Curr Top Microbiol Immunol. 2018;419:1-42.

10. de Wit E, van Doremalen N, Falzarano D, Munster VJ. SARS and MERS: recent insights into emerging coronaviruses. Nat Rev Microbiol. 2016;14:523-34.

11. http://www.chictr.org.cn/searchprojen.aspx.

12. Chan JFW, Yuan S, Kok KH, To KKW, Chu H, Yang J, et al. A familial cluster of pneumonia associated with the 2019 novel coronavirus indicating person-toperson transmission: a study of a family cluster. Lancet. 2020;395:514-23.

13. Diagnosis and Treatment Protocol for Novel Coronavirus Pneumonia (Trial Version 7).

14. https://www.who.int/emergencies/diseases/novel-coronavirus-2019.

15. Zhou CX, Xu FQ, Jiang SP. Advance in research on treatment of influenza viral pneumonia [in Chinese]. Chin J Nosocomiol. 2020;30:302-7.

16. Wang BX, Fish EN. The Yin and Yang of viruses and interferons. Trends Immunol. 2012;33:190-7.

17. McCarthy SD, Majchrzak-Kita B, Racine T, Kozlowski HN, Baker DP, Hoenen T, et al $A$ rapid screening assay identifies monotherapy with interferon-ss and combination therapies with nucleoside analogs as effective inhibitors of Ebola virus. PLoS Negl Trop Dis. 2016;10:e0004364.

18. Moriguchi $\mathrm{H}$, Sato $\mathrm{C}$. Treatment of SARS with human interferons. Lancet 2003;362:1159.

19. Chan JF, YY, Yeung ML, Deng W, Bao L, Jia L, et al. Treatment with lopinavir/ ritonavir or interferonbeta1b improves outcome of MERS-CoV infection in a nonhuman primate model of common marmoset. J Infect Dis. 2015;212:1904-13.

20. Cvetkovic RS, Goa KL. Lopinavir/ritonavir: a review of its use in the management of HIV infection. Drugs. 2003;63:769-802.

21. Sheahan TP, Sims AC, Leist SR, Schäfer A, Won J, Brown AJ, et al. Comparative therapeutic efficacy of remdesivir and combination lopinavir, ritonavir, and interferon beta against MERS-CoV. Nat Commun. 2020;11:222.

22. Chu CM, Cheng VCC, Hung IFN, Wong MML, Chan KH, Chan KS, et al. Role of lopinavir/ritonavir in the treatment of SARS: initial virological and clinical findings. Thorax. 2004;59:252-6.

23. Kim UJ, Won E-J, Kee S-J, Jung S-I, Jang H-C. Combination therapy with lopinavir/ ritonavir, ribavirin and interferon-a for Middle East respiratory syndrome. Antivir Ther. 2016;21:455-9.

24. Wu C-Y, Jan J-T, Ma S-H, Kuo C-J, Juan H-F, Cheng Y-SE, et al. Small molecules targeting severe acute respiratory syndrome human coronavirus. Proc Natl Acad Sci U S A. 2004;101:10012-7.

25. de Wilde AH, Jochmans D, Posthuma CC, Zevenhoven-Dobbe JC, van Nieuwkoop $\mathrm{S}$, Bestebroer TM, et al. Screening of an FDA-approved compound library identifies four small-molecule inhibitors of Middle East respiratory syndrome coronavirus replication in cell culture. Antimicrobial agents Chemother. 2014;58:4875-84.

26. Cao B, Wang Y, Wen D, Liu W, Wang J, Fan G, et al. A Trial of Lopinavir-Ritonavir in Adults Hospitalized with Severe Covid-19. N Engl J Med. 2020;382:1787-99.

27. Chen C, Zhang Y, Huang J, Yin P, Cheng Z, Wu J, et al. Favipiravir versus Arbido for COVID-19: A Randomized Clinical Trial. medRxiv 2020: 2020.03.17.20037432.

28. Beaucourt S, Vignuzzi M. Ribavirin: a drug active against many viruses with multiple effects on virus replication and propagation. Molecular basis of ribavirin resistance. Curr Opin Virol. 2014;8:10-5.

29. Trang TP, Whalen M, Hilts-Horeczko A, Doernberg SB, Liu C. Comparative effectiveness of aerosolized versus oral ribavirin for the treatment of respiratory syncytial virus infections: a single-center retrospective cohort study and review of the literature. Transpl Infect Dis. 2018;20:e12844.

30. Hézode C, Bronowicki J-P. Ideal oral combinations to eradicate HCV: the role of ribavirin. J Hepatol. 2016;64:215-25.

31. Lee $N$, Hui $D$, Wu A, Chan $P$, Cameron $P$, Joynt GM, et al. A major outbreak of severe acute respiratory syndrome in Hong Kong. $\mathrm{N}$ Engl J Med. 2003;348:1986-94.

32. Booth CM, Matukas LM, Tomlinson GA, Rachlis AR, Rose DB, Dwosh HA, et al. Clinical features and short-term outcomes of 144 patients with SARS in the greater Toronto area. JAMA. 2003;289:2801-9.

33. Chan JWM, Ng CK, Chan YH, Mok TYW, Lee S, Chu SYY, et al. Short term outcome and risk factors for adverse clinical outcomes in adults with severe acute respiratory syndrome (SARS). Thorax. 2003;58:686-9.

34. Sung JJY, Wu A, Joynt GM, Yuen KY, Lee N, Chan PKS, et al. Severe acute respiratory syndrome: report of treatment and outcome after a major outbreak. Thorax. 2004:59:414-20.

35. Morgenstern B, Michaelis M, Baer PC, Doerr HW, Cinatl J. Ribavirin and interferonbeta synergistically inhibit SARS-associated coronavirus replication in animal and human cell lines. Biochem Biophys Res Commun. 2005;326:905-8.

36. Omrani AS, Saad MM, Baig K, Bahloul A, Abdul-Matin M, Alaidaroos AY, et al. Ribavirin and interferon alfa-2a for severe Middle East respiratory syndrome coronavirus infection: a retrospective cohort study. Lancet Infect Dis. 2014;14:1090-5.
37. Savarino A. Use of chloroquine in viral diseases. Lancet Infect Dis. 2011;11:653-4.

38. Savarino A, Boelaert JR, Cassone A, Majori G, Cauda R. Effects of chloroquine on viral infections: an old drug against today's diseases? Lancet Infect Dis. 2003;3:722-7.

39. Wang M, Cao R, Zhang L, Yang X, Liu J, Xu M, et al. Remdesivir and chloroquine effectively inhibit the recently emerged novel coronavirus (2019-nCoV) in vitro. Cell Res. 2020;30:269-71.

40. Li F. Evidence for a common evolutionary origin of coronavirus spike protein receptor-binding subunits. J Virol. 2012;86:2856-8.

41. Vincent MJ, Bergeron E, Benjannet S, Erickson BR, Rollin PE, Ksiazek TG, et al. Chloroquine is a potent inhibitor of SARS coronavirus infection and spread. Viro J. 2005;2:69.

42. Guangsheng Su XG. Progress in antiviral therapy of new coronavirus pneumonia [in Chinese]. Chinese Journal of Difficult and Complicated Cases 2020; http://kns. cnki.net/kcms/detail/13.1316.R.20200226.0918.002.html.

43. Blaising J, Polyak SJ, Pécheur E-I. Arbidol as a broad-spectrum antiviral: an update. Antivir Res. 2014;107:84-94.

44. Boriskin YS, Leneva IA, Pécheur El, Polyak SJ. Arbidol: a broad-spectrum antiviral compound that blocks viral fusion. Curr Med Chem. 2008;15:997-1005.

45. Pécheur E-I, Borisevich V, Halfmann P, Morrey JD, Smee DF, Prichard M, et al. The synthetic antiviral drug arbidol inhibits globally prevalent pathogenic viruses. J Virol. 2016:90:3086-92.

46. Dawen Guan QD, Jiang Haiming, Zhao Jincun, Yang Zifeng. Comparison of inhibitory effects of arbidol and Lianhuaqingwen Capsules on Middle East respiratory syndrome coronavirus in vitro and in vivo[in Chinese]. Guangdong Med J. 2018;39:3454-8

47. Khamitov SIL RA, Shchukina VN, Borisevich SV, Maksimov VA, Shuster AM. [Antiviral activity of arbidol and its derivatives against the pathogen of severe acute respiratory syndrome in the cell cultures]. Vopr Virusol. 2008;53:9-13.

48. https://www.chinanews.com/gn/2020/02-04/9078596.shtml.

49. Wang Z, Chen X, Lu Y, Chen F, Zhang W. Clinical characteristics and therapeutic procedure for four cases with 2019 novel coronavirus pneumonia receiving combined Chinese and Western medicine treatment. Biosci Trends. 2020;14:64-8.

50. De Clercq E. Dancing with chemical formulae of antivirals: a personal account. Biochem Pharmacol. 2013;86:711-25.

51. De Clercq E. Dancing with chemical formulae of antivirals: A panoramic view (Part 2). Biochem Pharmacol. 2013;86:1397-410.

52. Furuta Y, Takahashi K, Kuno-Maekawa M, Sangawa H, Uehara S, Kozaki K, et al. Mechanism of action of T-705 against influenza virus. Antimicrob Agents Chemother. 2005:49:981-6.

53. De Clercq E. New nucleoside analogues for the treatment of hemorrhagic fever virus infections. Chem-Asian J. 2019;14:3962-8.

54. Mulangu S, Dodd LE, Davey RT, Tshiani Mbaya O, Proschan M, Mukadi D, et al. A randomized, controlled trial of Ebola virus disease therapeutics. N Engl J Med. 2019;381:2293-303.

55. Cihlar T, Ray AS. Nucleoside and nucleotide HIV reverse transcriptase inhibitors: 25 years after zidovudine. Antivir Res. 2010;85:39-58.

56. Eltahla $A A$, Luciani $F$, White PA, Lloyd AR, Bull RA. Inhibitors of the hepatitis $C$ virus polymerase; mode of action and resistance. Viruses. 2015;7:5206-24.

57. Tchesnokov EP, Feng JY, Porter DP, Gotte M. Mechanism of inhibition of Ebola virus RNA-dependent RNA polymerase by remdesivir. Viruses. 2019;11:326.

58. Agostini ML, Andres EL, Sims AC, Graham RL, Sheahan TP, Lu X, et al. Coronavirus susceptibility to the antiviral remdesivir (GS-5734) is mediated by the viral polymerase and the proofreading exoribonuclease. mBio. 2018;9:e00221-18.

59. Brown AJ, Won JJ, Graham RL, Dinnon KH, Sims AC, Feng JY, et al. Broad spectrum antiviral remdesivir inhibits human endemic and zoonotic deltacoronaviruses with a highly divergent RNA dependent RNA polymerase. Antivir Res. 2019;169:104541.

60. Sheahan TP, Sims AC, Graham RL, Menachery VD, Gralinski LE, Case JB, et al. Broad-spectrum antiviral GS-5734 inhibits both epidemic and zoonotic coronaviruses. Sci Transl Med. 2017;9:eaal3653.

61. Holshue ML, DeBolt $\mathrm{C}$, Lindquist $\mathrm{S}$, Lofy $\mathrm{KH}$, Wiesman J, Bruce $\mathrm{H}$, et al. First case of 2019 novel Coronavirus in the United States. N Engl J Med. 2020;382:929-36.

62. Schudt G, Dolnik O, Kolesnikova L, Biedenkopf N, Herwig A, Becker S. Transport of Ebolavirus nucleocapsids is dependent on actin polymerization: live-cell imaging analysis of Ebolavirus-infected cells. J Infect Dis. 2015;212(Suppl 2):S160-6.

63. Rainsford KD, Parke AL, Clifford-Rashotte M, Kean WF. Therapy and pharmacological properties of hydroxychloroquine and chloroquine in treatment of systemic lupus erythematosus, rheumatoid arthritis and related diseases. Inflammopharmacology. 2015;23:231-69.

64. Biot C, Daher W, Chavain N, Fandeur T, Khalife J, Dive D, et al. Design and synthesis of hydroxyferroquine derivatives with antimalarial and antiviral activities. J Med Chem. 2006:49:2845-9.

65. Yao X, Ye F, Zhang M, Cui C, Huang B, Niu $P$, et al. In vitro antiviral activity and projection of optimized dosing design of hydroxychloroquine for the treatment 
of severe acute respiratory syndrome Coronavirus 2 (SARS-CoV-2). Clin Infect Dis 2020; pii: ciaa237. https://doi.org/10.1093/cid/ciaa237.

66. Marmor MF, Kellner U, Lai TYY, Melles RB, Mieler WF. Recommendations on Screening for Chloroquine and Hydroxychloroquine Retinopathy (2016 Revision). Ophthalmology. 2016;123:1386-94.

67. Gautret $P$, Lagier JC, Parola P, Hoang VT, Meddeb L, Mailhe M, et al. Hydroxychloroquine and azithromycin as a treatment of COVID-19: results of an openlabel non-randomized clinical trial. Int J Antimicrob Agents. 2020:105949.

68. Chen Z, Hu J, Zhang Z, Jiang S, Han S, Yan D, et al. Efficacy of hydroxychloroquine in patients with COVID-19: results of a randomized clinical trial. medRxiv 2020: 2020.03.22.20040758.

69. Ji S, Bai Q, Wu X, Zhang DW, Wang S, Shen JL, et al. Unique synergistic antiviral effects of Shufeng Jiedu Capsule and oseltamivir in influenza A viral-induced acute exacerbation of chronic obstructive pulmonary disease. Biomed Pharmacother. 2020;121:109652.

70. Ding Y, Zeng L, Li R, Chen Q, Zhou B, Chen Q, et al. The Chinese prescription lianhuaqingwen capsule exerts anti-influenza activity through the inhibition of viral propagation and impacts immune function. BMC Complement Alternat Med. 2017;17:130.

71. Matsumoto $Y$, Matsuura T, Aoyagi H, Matsuda M, Hmwe SS, Date T, et al. Antiviral activity of glycyrrhizin against hepatitis C virus in vitro. PLoS One. 2013;8:e68992.

72. Cinatl J, Morgenstern B, Bauer G, Chandra P, Rabenau H, Doerr HW. Glycyrrhizin, an active component of liquorice roots, and replication of SARS-associated coronavirus. Lancet. 2003;361:2045-6.

73. Dezhong Cheng YL. Clinical effectiveness and case analysis in 54 NCP patients treated with Lianhuaqingwen Granules [in Chinese]. World Chin Med. 2020;15:150-4.

74. Yao KT, Liu MY, Li X, Huang JH, Cai HB. Retrospective clinical analysis on treatment of novel coronavirus-infected pneumonia with traditional chinese medicine Lianhua Qingwen [in Chinese]. Chin J Exp Tradit Med Formul 2020; http://kns.cnki. net/kcms/detail/11.3495.R.20200206.1500.004.html.
75. Lv RB, Wang WJ, Li X. Clinical observation on 63 cases of suspected cases of new Coronavirus pneumonia treated by Chinese Medicine Lianhua Qingwen [in Chinese]. J Tradit Chin Med 2020; http://kns.cnki.net/kcms/detail/11.2166. R.20200215.1633.004.html.

76. Chen F, Chan KH, Jiang Y, Kao RYT, Lu HT, Fan KW, et al. In vitro susceptibility of 10 clinical isolates of SARS coronavirus to selected antiviral compounds. J Clin Virol. 2004;31:69-75.

77. Ma X, Bi S, Wang Y, Chi X, Hu S. Combined adjuvant effect of ginseng stem-leaf saponins and selenium on immune responses to a live bivalent vaccine of Newcastle disease virus and infectious bronchitis virus in chickens. Poult Sci. 2019;98:3548-56.

78. Lan J, Ge J, Yu J, Shan S, Zhou H, Fan S, et al. Structure of the SARS-CoV-2 spike receptor-binding domain bound to the ACE2 receptor. Nature. 2020;581: 215-20.

79. Shang J, Ye G, Shi K, Wan Y, Luo C, Aihara H, et al. Structural basis of receptor recognition by SARS-CoV-2. Nature. 2020; https://doi.org/10.1038/s41586-0202179-y.

80. Wrapp D, Wang N, Corbett KS, Goldsmith JA, Hsieh CL, Abiona O, et al. Cryo-EM structure of the 2019-nCoV spike in the prefusion conformation. Science. 2020;367:1260-3.

81. Báez-Santos YM, St John SE, Mesecar AD. The SARS-coronavirus papain-like protease: structure, function and inhibition by designed antiviral compounds. Antivir Res. 2015;115:21-38.

82. Morse JS, Lalonde T, Xu S, Liu WR. Learning from the past: possible urgent prevention and treatment options for severe acute respiratory infections caused by 2019-nCoV. Chembiochem. 2020;21:730-8.

83. Ju J, Kumar S, Li X, Jockusch S, Russo JJ. Nucleotide analogues as inhibitors of viral polymerases. bioRxiv 2020: 2020.01.30.927574.

84. Hoffmann M, Kleine-Weber H, Schroeder S, Krüger N, Herrler T, Erichsen S, et al. SARS-CoV-2 cell entry depends on ACE2 and TMPRSS2 and is blocked by a clinically proven protease inhibitor. Cell. 2020;181:271-.e8. 